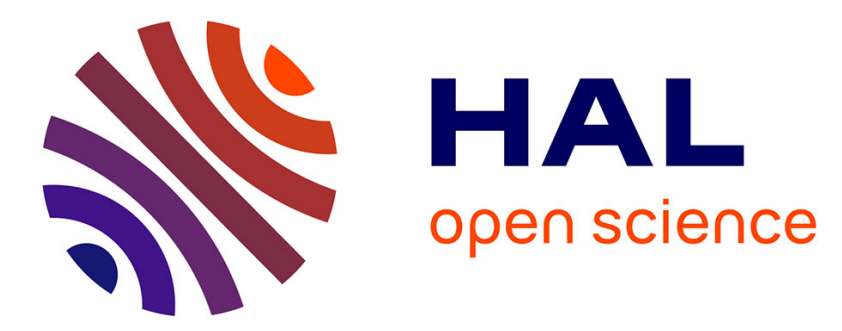

\title{
Liver X Receptor (LXR) activation negatively regulates visfatin expression in macrophages.
}

Thérèse Hèrvée Mayi, Elena Rigamonti, François Pattou, Bart Staels, Giulia Chinetti-Gbaguidi

\section{- To cite this version:}

Thérèse Hèrvée Mayi, Elena Rigamonti, François Pattou, Bart Staels, Giulia Chinetti-Gbaguidi. Liver X Receptor (LXR) activation negatively regulates visfatin expression in macrophages.. Biochemical and Biophysical Research Communications, 2011, 404 (1), pp.458-62. 10.1016/j.bbrc.2010.12.002 . inserm-00554308

\section{HAL Id: inserm-00554308 https://www.hal.inserm.fr/inserm-00554308}

Submitted on 10 Jan 2011

HAL is a multi-disciplinary open access archive for the deposit and dissemination of scientific research documents, whether they are published or not. The documents may come from teaching and research institutions in France or abroad, or from public or private research centers.
L'archive ouverte pluridisciplinaire HAL, est destinée au dépôt et à la diffusion de documents scientifiques de niveau recherche, publiés ou non, émanant des établissements d'enseignement et de recherche français ou étrangers, des laboratoires publics ou privés. 


\title{
LIVER X RECEPTOR (LXR) ACTIVATION NEGATIVELY REGULATES VISFATIN EXPRESSION IN MACROPHAGES
}

\author{
Thérèse Hèrvée Mayi ${ }^{1,2,3,4}$, Elena Rigamonti ${ }^{1,2,3,4}$, François Pattou ${ }^{1,5,6}$, Bart Staels ${ }^{1,2,3,4}$ \\ and Giulia Chinetti-Gbaguidi ${ }^{1,2,3,4}$
}

\footnotetext{
${ }^{1}$ Univ Lille Nord de France, F-59000, Lille, France

${ }^{2}$ Inserm, U1011, F-59000, Lille, France

${ }^{3}$ UDSL, F-59000, Lille, France

${ }^{4}$ Institut Pasteur de Lille, F-59019, Lille, France

${ }^{5}$ Department of Endocrine Surgery, University Hospital, Lille, France

${ }^{6}$ U859 Biotherapies for diabetes, INSERM, Lille, France
}

Address correspondence to:

Bart Staels

Inserm UR 1011, Institut Pasteur de Lille

1, rue du Professeur Calmette, BP 245, Lille 59019, France

Tel: +33-3-20-87-73-88; Fax: +33-3-20-87-73-60

E-mail : bart.staels@pasteur-lille.fr 


\section{ABSTRACT}

Adipose tissue macrophages (ATM) are the major source of visfatin, a visceral fat adipokine upregulated during obesity. Also known to play a role in B cell differentiation (pre-B cell colony-enhancing factor $(\mathrm{PBEF})$ ) and NAD biosynthesis (nicotinamide phosphoribosyl transferase (NAMPT)), visfatin has been suggested to play a role in inflammation.

Liver X Receptor (LXR) and Peroxisome Proliferator-Activated Receptor (PPAR) $\gamma$ are nuclear receptors expressed in macrophages controlling the inflammatory response. Recently, we reported visfatin as a PPAR $\gamma$ target gene in human macrophages. In this study, we examined whether LXR regulates macrophage visfatin expression. Synthetic LXR ligands decreased visfatin gene expression in a LXR-dependent manner in human and murine macrophages. The decrease of visfatin mRNA was paralleled by a decrease of protein secretion. Consequently, a modest and transient decrease of NAD+ concentration was observed. Interestingly, LXR activation decreased the PPAR $\gamma$-induced visfatin gene and protein secretion in human macrophages.

Our results identify visfatin as a gene oppositely regulated by the LXR and PPAR $\gamma$ pathways in human macrophages.

KEYWORDS - nuclear receptors, adipocytokines, visfatin, inflammation, macrophages 


\section{INTRODUCTION}

Visfatin/PBEF/NAMPT is a cytokine secreted by adipocytes and preferentially by macrophages in adipose tissue, which circulates in both human and murine plasma [1]. Visfatin was originally described as a cytokine-like molecule that promotes pre-B cell colony formation in vitro [2]. Later on, visfatin was identified as nicotinamide phosphoribosyl transferase (NAMPT), a rate-limiting enzyme in the synthesis of nicotinamide adenine dinucleotide (NAD+) from nicotinamide, thus acting as an extra- and intracellular NAD biosynthetic enzyme that converts nicotinamide (NAM, a form of vitamin B3) to nicotinamide mononucleotide (NMN), a NAD precursor, in mammals [3]. Visfatin expression is induced by inflammatory stimuli such as interleukin-1beta (IL-1 $\beta$ ), tumor necrosis factor alpha (TNF $\alpha)$ and interleukin-6 (IL-6) in monocytes and macrophages [4-6]. Conversely, visfatin has been shown to regulate the production of IL-1 $\beta$, IL- 6 and TNF $\alpha$ in peripheral blood mononuclear cells, suggesting a potential role in the pathogenesis of inflammation-related disorders.

Many macrophage functions are regulated by transcription factors such as the nuclear receptors, including the Liver X Receptors (LXR $\alpha$ and LXR $\beta$ ) and the Peroxisome Proliferator-Activated Receptor (PPAR) $\gamma$ [7]. LXR and PPAR $\gamma$ are ligand-activated nuclear receptors inhibiting the inflammatory response and participating in the control of transcription of genes involved in lipid and glucose metabolism. After activation by their ligands, LXR and PPAR $\gamma$ heterodimerize with Retinoic X Receptor (RXR) and bind to specific DNA sequences called LXR response elements (LXRE) or PPAR response elements (PPRE), respectively [8]. LXR are activated by natural (oxysterols) or synthetic ligands such as T0901317 and GW3965, while PPAR $\gamma$ is activated by natural 15-deoxy-D12;14-prostaglandin J2 (15d-PGJ2), and synthetic ligands, glitazones and the GW1929 compound [8]. Furthermore, when activated by their agonists, LXR and PPAR $\gamma$ inhibit the cytokine-induced expression of inflammatory genes 
by negatively interfering with the NF- $\kappa \mathrm{B}$, STAT and AP-1 signaling pathways in a DNAbinding independent manner (for review [8]).

Recently, we have reported that visfatin is a PPAR $\gamma$ target gene in human macrophages [9]. Here we investigated whether visfatin expression is also regulated by LXR activation. We demonstrate that LXR activation decreases macrophage visfatin gene expression in a LXRdependent manner. This leads to a transient decrease in NAD+ concentration. Interestingly, LXR activation also decreases visfatin gene expression and protein secretion induced by PPAR $\gamma$ agonists. 


\section{MATERIALS AND METHODS}

\section{Cell culture}

Monocytes from healthy normolipidemic or obese humans were isolated by Ficoll gradient centrifugation and primary macrophages obtained after 10 days of differentiation [10]. Macrophages were incubated in the presence of LXR ligands T0901317 (1 $\mu \mathrm{M})$, GW3965 (1 $\mu \mathrm{M})$ or DMSO for the indicated times $(3,6,12$ or $24 \mathrm{~h})$ or with $\mathrm{T} 0901317(0.25,0.5,1 \mu \mathrm{M})$ for 24h. In some experiments, macrophages were co-treated with T0901317 (1 $\mu \mathrm{M})$ and recombinant human TNF $\alpha$ or human IL-1 $\beta$ (5 ng/ml, Promokines) for $6 \mathrm{~h}$. In parallel experiments, macrophages were pre-treated with T0901317 $(1 \mu \mathrm{M})$ for $6 \mathrm{~h}$ and then stimulated with IL-1 $\beta(5 \mathrm{ng} / \mathrm{ml})$ for $2 \mathrm{~h}$. Where indicated, macrophages were incubated with the PPAR $\gamma$ ligand GW1929 (600 nM) for 24h and then treated with T0901317 $(1 \mu \mathrm{M})$ for a further $6 \mathrm{~h}$.

Murine bone marrow-derived macrophages (BMDM) were prepared from C57BL/6J mice as described [11] and treated with T0901317 (2 $\mu \mathrm{M})$ for $24 \mathrm{~h}$.

Human ATM were isolated as previously reported [9] from visceral adipose tissue biopsies of obese patients undergoing bariatric surgery (ABOS project approved by the Ethical committee and the Federation of clinical research of CHRU of Lille, France). ATM were cultured for 24h in Endothelial Cell Basal Medium (Promocell) supplemented with $0.1 \%$ BSA [12] before treatment with T0901317 $(1 \mu \mathrm{M})$ or GW3965 $(1 \mu \mathrm{M})$.

\section{RNA extraction and analysis}

Total cellular RNA was extracted from macrophages and ATM using Trizol (Invitrogen, France) or RNeasy micro kit (Qiagen), respectively, and reverse transcribed using High Capacity cDNA Reverse Transcription kit (Applied Biosystems, USA). cDNAs were quantified by quantitative polymerase chain reaction (Q-PCR) on a MX 4000 apparatus (Agilent Biotechnologies) using Brilliant II SYBR® Green QPCR Master Mix kit 
supplemented with specific primers for human visfatin (5'-GCCAGCAGGGAATTTTGTTA3' forward and 5'-TGATGTGCTGCTTCCAGTTC-3'reverse), mouse visfatin (5'TCCGGCCCGAGATGAAT-3' forward and GTGGGTATTGTTTATAGTGAGTAACCTTGT-3' reverse ) and human/mouse cyclophilin (5'-GCATACGGGTCCTGGCATCTTGTC C-3'forward 5'ATGGTGATCTTCTTGCTGGTCTTGC-3' reverse). Visfatin mRNA levels were normalized to cyclophilin mRNA.

\section{Short-Interfering RNA}

Human macrophages were transfected with specific siRNA for human LXR $\alpha$ and LXR $\beta$ (SMARTpool siRNA) and non-silencing control siRNA using the transfection reagent DharmaFECT Reagent 4 (Dharmacon). 16h after transfection, cells were incubated with T0901317 $(1 \mu \mathrm{M})$ or vehicle (DMSO) and harvested 24h later.

\section{Measure of visfatin protein secretion}

Human macrophages and ATM were treated with LXR ligands T0901317 (1 $\mu$ M), GW3965 $(1 \mu \mathrm{M})$ or DMSO for $24 \mathrm{~h}$. Supernatants were collected and extracellular visfatin concentrations measured using a commercially available ELISA kit (Phoenix Pharmaceuticals, Germany).

\section{Measure of NAD cellular content}

Total nicotinamide adenine dinucleotide $(\mathrm{NADt}=\mathrm{NAD}+\mathrm{NADH})$ levels were determined in cell lysates using a specific NADH/NAD quantification kit (Biovision research products). Briefly, human macrophages were treated with T0901317 $(1 \mu \mathrm{M})$ or DMSO for 6 or 24h and the NAD/NADH ratio was calculated as (NADt-NADH)/NADH. NAD levels were normalized to protein content. Results are expressed as percentage, the control non-stimulated 
cells being expressed as $100 \%$. All assays were done in triplicate in at least three independent experiments.

\section{Statistical analysis}

Statistical differences between groups were analysed by Student's $t$ tests and were considered significant when $\mathrm{p} \leq 0.05$. 


\section{RESULTS}

\section{LXR activation decreases visfatin gene expression in a LXR-dependent manner in macrophages}

To determine whether LXR might affect the expression of visfatin in macrophages, QPCR analysis was performed on RNA isolated from primary human macrophages treated during 3, 6, 12 and 24h with LXR ligands. Treatment with either T0901317 (1 $\mu \mathrm{M})$ or GW3965 $(1 \mu \mathrm{M})$ resulted in a significant repression of visfatin gene expression, reaching a plateau of about 50\% inhibition after 3 or 6h treatment with GW3965 or T0901317, respectively (figure 1A). Treatment with increasing concentrations of T0901317 (0.25, 0.5 and $1 \mu \mathrm{M}$ ) did not further inhibit the expression of visfatin, which was almost maximal at the concentration of $0.25 \mu \mathrm{M}$ (figure 1B). To investigate whether regulation of visfatin expression by LXR can also be extended to mouse macrophages, Q-PCR analysis was performed on RNA isolated from BMDM treated with T0901317 $(2 \mu \mathrm{M})$ (figure 1C). Visfatin mRNA expression was decreased by T0901317 also in murine BMDM. Similar results were obtained upon LXR activation in the murine macrophage cell line RAW264.7 (data not shown).

Since it has been reported that visfatin is a visceral fat adipokine mainly produced by ATM, the expression of visfatin mRNA in macrophages and visceral ATM was compared. QPCR analysis revealed that visfatin was 6-fold higher expressed in ATM than in monocytederived macrophages (MDM) from the same obese donors (figure 1D). To determine whether LXR activation affects the expression of visfatin in ATM, Q-PCR analysis was performed on ATM treated with T0901317 $(1 \mu \mathrm{M})$ or GW3965 $(1 \mu \mathrm{M})$ for $24 \mathrm{~h}$. Visfatin mRNA was decreased by LXR agonists to a similar extent as in MDM (figure 1E).

To address whether the inhibitory effect of LXR ligands on visfatin gene expression is mediated by LXR, a siRNA approach was used. The effect of T0901317 (1 $\mu \mathrm{M})$ was analyzed in the presence or in the absence of siRNA targeting LXR $\alpha / \beta$. Visfatin induction upon LXR 
activation was completely lost in LXR $\alpha / \beta$ siRNA-transfected macrophages compared to scrambled siRNA-transfected cells (figure $1 \mathrm{~F}$ ), indicating that the reduction of visfatin mRNA expression by T0901713 occurs via LXR activation.

\section{LXR activation decreases visfatin gene expression induced by inflammatory cytokines}

Since the expression of visfatin has been shown to be induced by inflammatory stimuli in macrophages [13], we decided to investigate whether LXR activation could block the induction of visfatin by inflammatory cytokines. Macrophages were activated or not with TNF $\alpha$ or IL1- $\beta$ during $6 \mathrm{~h}$. As expected, visfatin expression was stimulated by these cytokines. Moreover, the stimulatory effect of TNFa on visfatin gene expression was less prominent than IL1- $\beta$, consistent with previous data derived from rheumatoid arthritis synovial fibroblasts [14]. Co-treatment of activated-macrophages with T0901317 for 6h repressed the cytokine-induced visfatin expression (figure 2A).

To determine whether LXR activation can also prevent cytokine-induced visfatin expression, macrophages were pre-treated for $6 \mathrm{~h}$ with T0901317 $(1 \mu \mathrm{M})$ and subsequently activated with IL1- $\beta$ for $2 h$. Our results show that pre-treatment with LXR ligand reduced the IL-1 $\beta$-induced visfatin mRNA (figure 2B).

\section{LXR activation decreases visfatin protein secretion and intracellular $\mathrm{NAD}^{+}$concentration in human macrophages}

To determine whether LXR agonists also regulate visfatin protein levels, the secretion of visfatin was analyzed in MDM and ATM treated or not with LXR ligands. Treatment with either T0901317 $(1 \mu \mathrm{M})$ or GW3965 $(1 \mu \mathrm{M})$ for $24 \mathrm{~h}$ significantly decreased visfatin release in MDM and ATM (figure 3A and 3B). 
To investigate whether the inhibition of visfatin by LXR ligands could affect the intracellular $\mathrm{NAD}^{+}$concentration, macrophages were treated or not with $\mathrm{T} 0901317(1 \mu \mathrm{M})$ for 6 or $24 \mathrm{~h}$ and intracellular $\mathrm{NAD}^{+}$level determined by enzymatic assay. LXR activation reduced the basal level of intracellular $\mathrm{NAD}^{+}$concentration (figure 3C).

\section{LXR activation decreases PPAR $\gamma$-induced visfatin gene expression and protein secretion in human macrophages.}

We previously reported that PPAR $\gamma$ agonists induce the expression and secretion of visfatin in a PPAR $\gamma$-dependent manner in human macrophages [9]. To investigate whether LXR activation could repress the induction of visfatin by PPAR $\gamma$ activation, macrophages were treated with the PPAR $\gamma$ agonist GW1929 (600 nM) for $24 \mathrm{~h}$ and further activated for $6 \mathrm{~h}$ in the presence or absence of T0901317 $(1 \mu \mathrm{M})$. LXR activation clearly reduced visfatin gene expression and protein secretion induced by the GW929 compound (figure 4A and 4B). These

results suggest that a potential negative LXR/PPAR $\gamma$ cross-talk exists on the regulation of visfatin expression in macrophages. 


\section{DISCUSSION}

In adipose tissue (AT), visfatin is an inflammatory response cytokine mainly produced by macrophages [1]. In line, visfatin has been suggested to act as an inflammatory mediator, expressed in monocytes and lipid loaded- macrophages within unstable atherosclerotic lesions where it potentially plays a role in plaque destabilization $[4,15]$. We previously reported that PPAR $\gamma$ positively regulates visfatin expression in human macrophages [9]. The objective of this study was to determine whether the nuclear receptor LXR controls the visfatin expression in macrophages.

Our results show that LXR activation with both LXR ligands GW3965 and T0901317 downregulates the expression of visfatin in macrophages, reaching a maximal effect very rapidly (6h). Interestingly, we also found that LXR activation decreases the expression of visfatin mRNA in murine macrophages (BMDM).

Since visfatin is a visceral adipose fat adipokine mainly produced by ATM [1], visfatin gene expression was compared in monocyte-derived macrophages (MDM) and visceral ATM isolated from the same obese donors. Visfatin mRNA level was found to be 6-fold higher in ATM than in MDM and was also down-regulated by LXR activation. Specifically knock-down of LXR $\alpha / \beta$ with siRNA demonstrated that the LXR agonists repress visfatin gene expression in a LXR-dependent manner. Previous studies have shown that visfatin expression is induced by inflammatory stimuli such as IL1- $\beta$ and TNF $\alpha$ in macrophages [13]. Interestingly, pretreatment or co-treatment of inflammatory macrophages with LXR ligand T0901317 blocked the visfatin gene induction by these cytokines, probably via mechanisms resembling its antiinflammatory properties. Thus, the regulation of visfatin, itself an "inflammatory cytokinelike" adipokine could contribute to the inflammatory response to inflammatory cytokines such as IL1- $\beta$ and TNF $\alpha$ via AP-1 and NF- $\kappa$ B activation [16] and to the anti-inflammatory action of LXR agonists. 
LXR agonists reduced visfatin protein secretion and mRNA levels in MDM and ATM to a similar extent. LXR activation reduced intracellular NAD+ concentration to a comparable extent as previously observed in NIH-3T3 murine fibroblasts transduced with visfatin specific shRNA, leading to $20-40 \%$ of NAD reduction, whereas cells over-expressing visfatin increased total intracellular NAD+ levels by $15-25 \%[17]$. We suggest that the slightly decrease of intracellular $\mathrm{NAD}^{+}$concentration by LXR agonists is the consequence of visfatin mRNA reduction. Based on the large body of evidence suggesting a major role for NAD in controlling cell survival, altered NAD metabolism can directly affect macrophage lifespan [17]. NAD+ is a cofactor of many deacetylases of the Sirtuin family, especially SIRT1. For instance low to moderate overexpression of SIRT1 in transgenic mouse hearts attenuated agedependent increases in cardiac hypertrophy, apoptosis/fibrosis, cardiac dysfunction, and expression of senescence markers. In contrast, a high level of Sirt1 increased apoptosis and hypertrophy and decreased cardiac function, thereby stimulating the development of cardiomyopathy [18]. SIRT6, another member of the sirtuin family, has been identified as a NAD-dependent enzyme able to increase $\mathrm{TNF} \alpha$ production in macrophages by acting at a post-transcriptional level [19]. Taken together these observations suggest that NAD+ can exert pro- and/or anti-inflammatory properties depending on the activated sirtuins.

Interestingly, LXR activation blocks visfatin gene expression and secretion induced by PPAR $\gamma$. To our knowledge, this is the first gene regulated in an opposite manner by LXR and PPAR $\gamma$ in macrophages. Further studies are required to determine the molecular mechanisms behind this negative cross-talk between LXR and PPAR $\gamma$. 


\section{ACKNOWLEDGMENTS}

We thank A. Blondy, C. Eberle, MF. Six and L. Arnalsteen for their assistance and K. Bertrand (Genfit, France) for providing the T0901317 and GW3965 compounds. The research leading to these results has received funding from the European Community's 7th Framework Programme (FP7/2007-2013) under grant agreement $n^{\circ}$ 201608, the "Nouvelle Societé Française d'Athérosclérose" (to T.H. Mayi) and the "Fondation Coeur et Artères". 


\section{REFERENCES}

[1] C. A. Curat, V. Wegner, C. Sengenes, A. Miranville, C. Tonus, R. Busse, and A. Bouloumie, Macrophages in human visceral adipose tissue: increased accumulation in obesity and a source of resistin and visfatin, Diabetologia 49 (2006) 744-747.

[2] B. Samal, Y. Sun, G. Stearns, C. Xie, S. Suggs, and I. McNiece, Cloning and characterization of the cDNA encoding a novel human pre-B-cell colony-enhancing factor, Mol Cell Biol 14 (1994) 1431-1437.

[3] J. R. Revollo, A. Korner, K. F. Mills, A. Satoh, T. Wang, A. Garten, B. Dasgupta, Y. Sasaki, C. Wolberger, R. R. Townsend, J. Milbrandt, W. Kiess, and S. Imai, $\mathrm{Nampt} / \mathrm{PBEF} / \mathrm{Visfatin}$ regulates insulin secretion in beta cells as a systemic NAD biosynthetic enzyme, Cell Metab 6 (2007) 363-375.

[4] T. B. Dahl, A. Yndestad, M. Skjelland, E. Oie, A. Dahl, A. Michelsen, J. K. Damas, S. H. Tunheim, T. Ueland, C. Smith, B. Bendz, S. Tonstad, L. Gullestad, S. S. Froland, K. KrohgSorensen, D. Russell, P. Aukrust, and B. Halvorsen, Increased expression of visfatin in macrophages of human unstable carotid and coronary atherosclerosis: possible role in inflammation and plaque destabilization, Circulation 115 (2007) 972-980.

[5] A. R. Moschen, A. Kaser, B. Enrich, B. Mosheimer, M. Theurl, H. Niederegger, and H. Tilg, Visfatin, an adipocytokine with proinflammatory and immunomodulating properties, $\mathrm{J}$ Immunol 178 (2007) 1748-1758.

[6] C. E. Kendal, and G. D. Bryant-Greenwood, Pre-B-cell colony-enhancing factor (PBEF/Visfatin) gene expression is modulated by NF-kappaB and AP-1 in human amniotic epithelial cells, Placenta 28 (2007) 305-314.

[7] G. Chinetti-Gbaguidi, and B. Staels, Lipid ligand-activated transcription factors regulating lipid storage and release in human macrophages, Biochim Biophys Acta 1791 (2009) 486493.

[8] E. Rigamonti, G. Chinetti-Gbaguidi, and B. Staels, Regulation of macrophage functions by PPAR-alpha, PPAR-gamma, and LXRs in mice and men, Arterioscler Thromb Vasc Biol 28 (2008) 1050-1059.

[9] T. H. Mayi, C. Duhem, C. Copin, M. A. Bouhlel, E. Rigamonti, F. Pattou, B. Staels, and G. Chinetti-Gbaguidi, Visfatin is induced by peroxisome proliferator-activated receptor gamma in human macrophages, Febs J 277 (2010) 3308-3320.

[10] G. Chinetti, S. Griglio, M. Antonucci, I. Pineda Torra, P. Delerive, Z. Majd, J. C. Fruchart, J. Chapman, J. Najib, and B. Staels, Activation of peroxisome proliferator-activated receptors $\alpha$ and $\gamma$ induces apoptosis of human monocyte-derived macrophages., J. Biol. Chem. 273 (1998) 25573-25580.

[11] N. Wang, D. Lan, W. Chen, F. Matsuura, and A. R. Tall, ATP-binding cassette transporters G1 and G4 mediate cellular cholesterol efflux to high-density lipoproteins, Proc. Natl. Acad. Sci. USA (2004) 9774-9779.

[12] C. A. Curat, A. Miranville, C. Sengenes, M. Diehl, C. Tonus, R. Busse, and A. Bouloumie, From blood monocytes to adipose tissue-resident macrophages: induction of diapedesis by human mature adipocytes, Diabetes 53 (2004) 1285-1292.

[13] J. Iqbal, and M. Zaidi, TNF regulates cellular NAD+ metabolism in primary macrophages, Biochem Biophys Res Commun 342 (2006) 1312-1318.

[14] F. Brentano, O. Schorr, C. Ospelt, J. Stanczyk, R. E. Gay, S. Gay, and D. Kyburz, Pre-B cell colony-enhancing factor/visfatin, a new marker of inflammation in rheumatoid arthritis with proinflammatory and matrix-degrading activities, Arthritis Rheum 56 (2007) 2829-2839.

[15] S. H. Jia, Y. Li, J. Parodo, A. Kapus, L. Fan, O. D. Rotstein, and J. C. Marshall, Pre-B cell colony-enhancing factor inhibits neutrophil apoptosis in experimental inflammation and clinical sepsis, J Clin Invest 113 (2004) 1318-1327. 
[16] S. R. Kim, Y. H. Bae, S. K. Bae, K. S. Choi, K. H. Yoon, T. H. Koo, H. O. Jang, I. Yun, K. W. Kim, Y. G. Kwon, M. A. Yoo, and M. K. Bae, Visfatin enhances ICAM-1 and VCAM1 expression through ROS-dependent NF-kappaB activation in endothelial cells, Biochim Biophys Acta 1783 (2008) 886-895.

[17] A. Rongvaux, M. Galli, S. Denanglaire, F. Van Gool, P. L. Dreze, C. Szpirer, F. Bureau, F. Andris, and O. Leo, Nicotinamide phosphoribosyl transferase/pre-B cell colony-enhancing factor/visfatin is required for lymphocyte development and cellular resistance to genotoxic stress, J Immunol 181 (2008) 4685-4695.

[18] R. R. Alcendor, S. Gao, P. Zhai, D. Zablocki, E. Holle, X. Yu, B. Tian, T. Wagner, S. F. Vatner, and J. Sadoshima, Sirt1 regulates aging and resistance to oxidative stress in the heart, Circ Res 100 (2007) 1512-1521.

[19] F. Van Gool, M. Galli, C. Gueydan, V. Kruys, P. P. Prevot, A. Bedalov, R. Mostoslavsky, F. W. Alt, T. De Smedt, and O. Leo, Intracellular NAD levels regulate tumor necrosis factor protein synthesis in a sirtuin-dependent manner, Nat Med 15 (2009) 206-210. 


\section{FIGURE LEGENDS}

Figure 1: LXR activation decreases visfatin gene expression in macrophages in a LXR dependent manner.

Human monocyte-derived macrophages (MDM) were incubated or not (control) with (A) LXR ligands T0901317 (1 $\mu \mathrm{M})$, GW3965 (1 $\mu \mathrm{M})$ for the indicated times, or (B) with T0901317 (0.25, 0.5, $1 \mu \mathrm{M})$ for 24h. (C), Mouse BMDM were treated or not with T0901317 $(2 \mu \mathrm{M})$ for $24 \mathrm{~h}$. (D), MDM and ATM were isolated from the same obese patients. (E), ATM were treated with T0901317 $(1 \mu \mathrm{M})$ or GW3965 $(1 \mu \mathrm{M})$ for $24 \mathrm{~h}$. (F) Macrophages were transfected with non-silencing control or LXR $\alpha / \beta$ siRNA and then treated with or without T0901317 $(1 \mu \mathrm{M})$ for 24h. Visfatin mRNA was analyzed by Q-PCR and normalized to cyclophilin mRNA. Results are representative of those obtained from 3 independent macrophage preparations and are expressed relative to the control cells set as 1. Each bar is the mean value \pm SD of triplicate determinations. Statistically significant differences are indicated (t-test; $* \mathrm{p}<0.05 ; * * \mathrm{p}<0.01 ; * * * \mathrm{p}<0.001)$.

Figure 2. LXR activation decreases cytokine-induced visfatin gene expression in human macrophages.

(A) MDM were stimulated for $6 \mathrm{~h}$ or not with human TNF $\alpha$ or IL-1 $\beta(5 \mathrm{ng} / \mathrm{ml})$ in the presence or in the absence of T0901317 $(1 \mu \mathrm{M})$. (B) Macrophages were pre-treated for $6 \mathrm{~h}$ or not with T0901317 $(1 \mu \mathrm{M})$ and then activated with $\mathrm{IL}-1 \beta(5 \mathrm{ng} / \mathrm{ml})$ for $2 \mathrm{~h}$. Visfatin mRNA was analyzed by Q-PCR and normalized to cyclophilin mRNA. Results are representative of those obtained from 3 independent macrophage preparations and expressed relative to the levels in untreated cells set as 1 . Each bar is the mean value $\pm \mathrm{SD}$ of triplicate determinations. Statistically significant differences are indicated (control vs cytokines $* \mathrm{p}<0.05 ; * * \mathrm{p}<0.01$; cytokines vs LXR agonists $\left.{ }^{\S} \mathrm{p}<0.05 ;{ }^{\S} \mathrm{p}<0.01\right)$. 
Figure 3: LXR activation decreases visfatin secretion and affects intracellular NAD concentration in human macrophages.

MDM (A) and ATM (B) were treated or not with T0901317 $(1 \mu \mathrm{M})$ or GW3965 $(1 \mu \mathrm{M})$ for 24h and visfatin protein secretion quantified in supernatant by ELISA. (C) Macrophages were treated or not with T0901317 $(1 \mu \mathrm{M})$ during 6 or $24 \mathrm{~h}$ and NAD concentrations measured by an enzymatic cycling reaction assay and normalized to protein levels and expressed as percentage, the control non-stimulated cells being expressed as 100\%. Results are representative of 3 independent macrophage preparations. Each bar is the mean value \pm SD of triplicate determinations. Statistically significant differences are indicated $(* \mathrm{p}<0.05$; $* * \mathrm{p}<0.01 ; * * * \mathrm{p}<0.001)$

Figure 4: LXR activation blocks PPAR $\gamma$-induced visfatin gene expression and secretion in human macrophages.

Macrophages were treated with the PPAR $\gamma$ ligand GW1929 (600 nM) during 24h followed by the addition of T0901317 $(1 \mu \mathrm{M})$ for $6 \mathrm{~h}$, or with each compounds alone and visfatin mRNA (A) and protein secretion (B) measured. Each bar is the mean value \pm SD of triplicate determinations. Statistically significant differences are indicated (control vs PPAR $\gamma$ agonists ${ }^{*} \mathrm{p}<0.05 ;{ }^{*} \mathrm{p}<0.01 ;$ PPAR $\gamma$ agonists vs PPAR $\gamma / \mathrm{LXR}$ agonists $\left.{ }^{\S \S} \mathrm{p}<0.05 ;{ }^{\S \S \S} \mathrm{p}<0.01\right)$. 

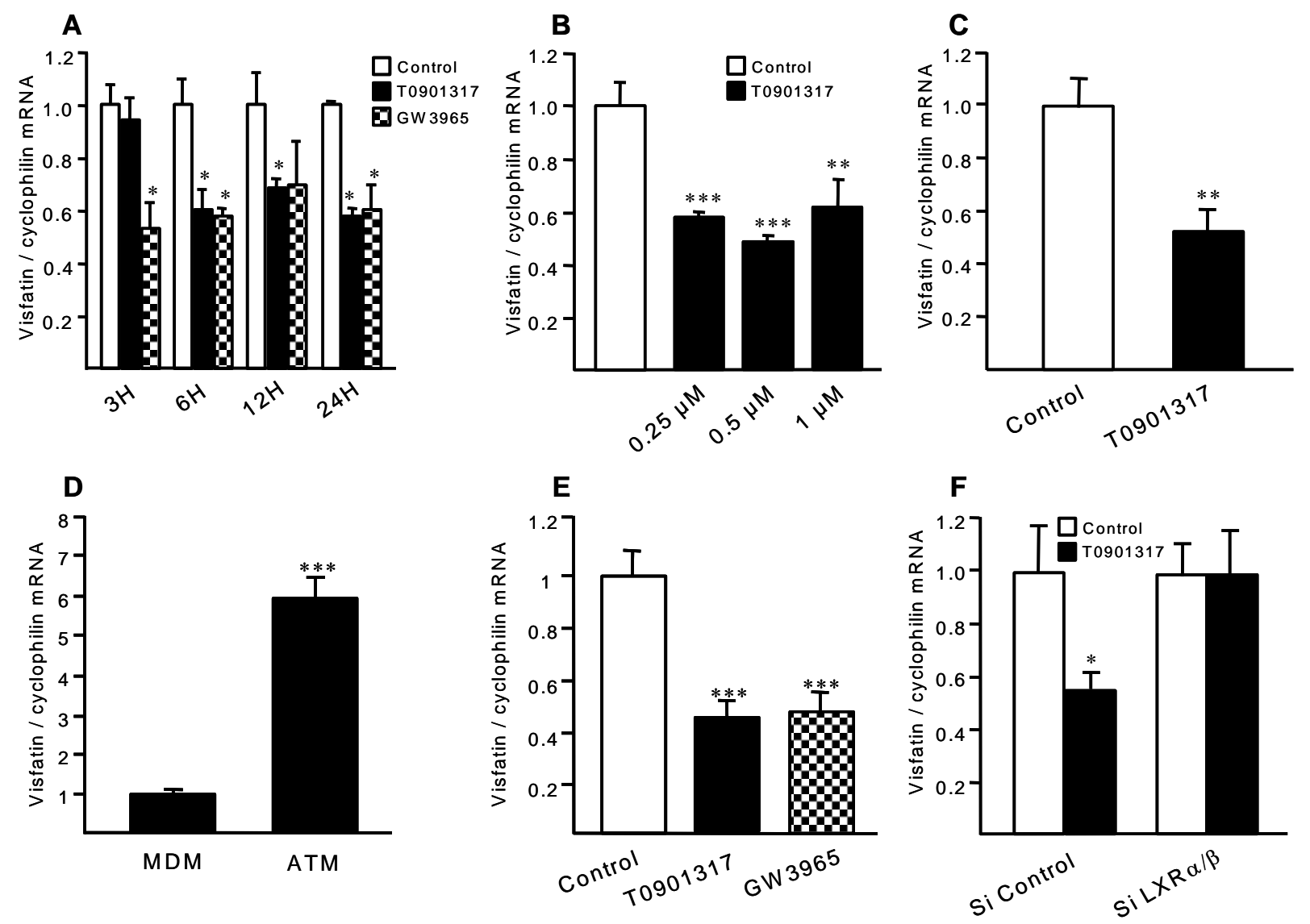

Figure 1 

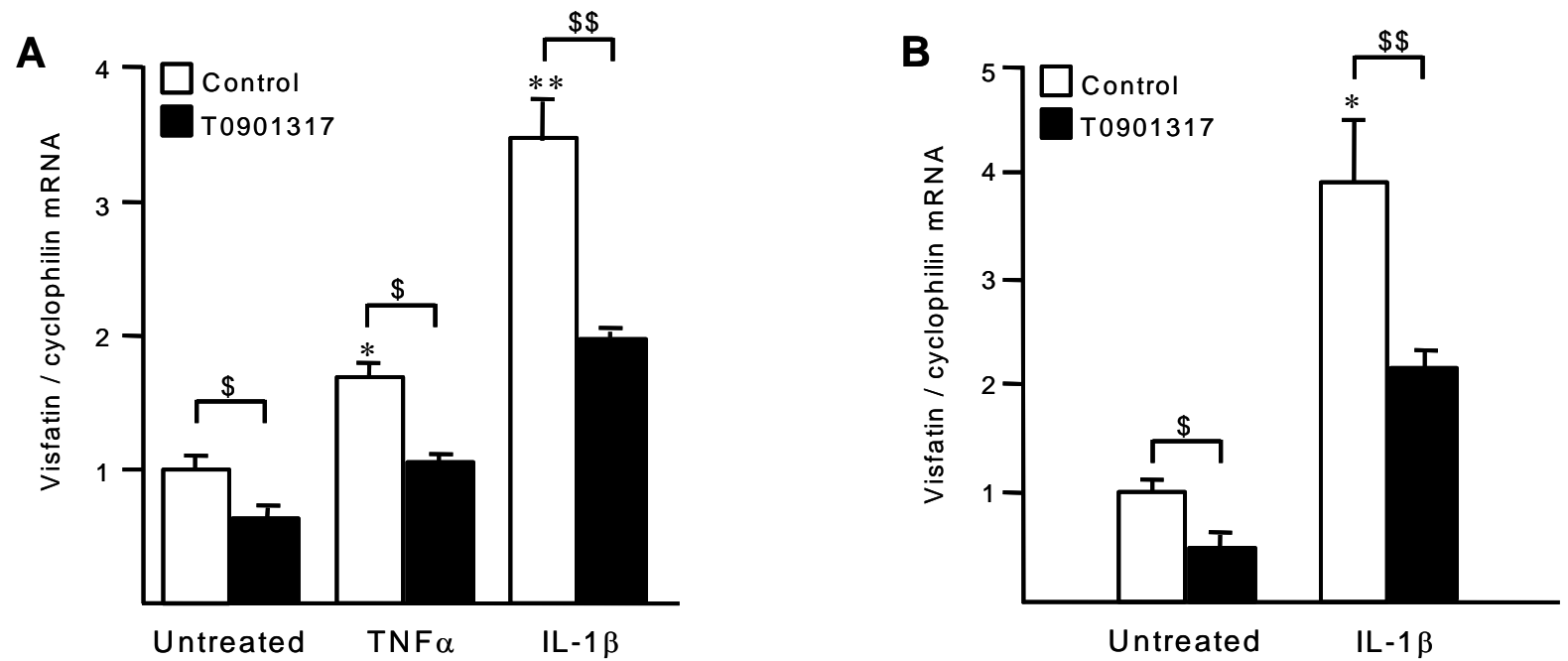

Figure 2 

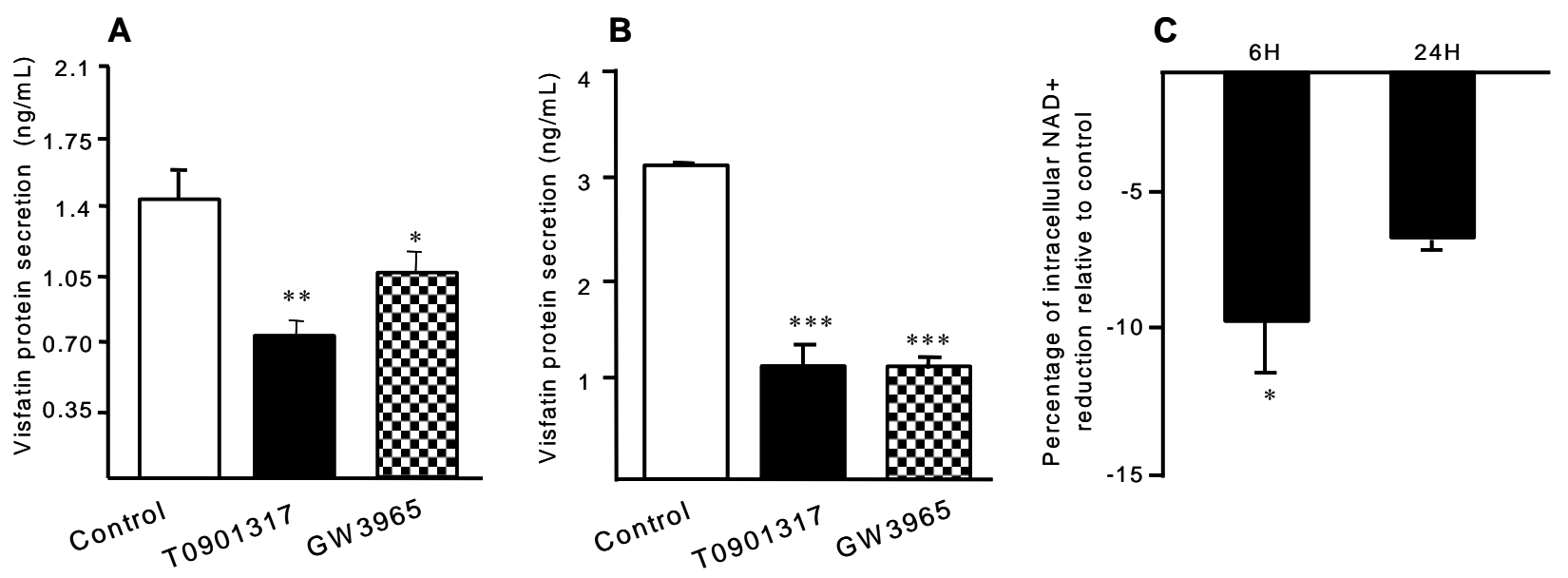

Figure 3 

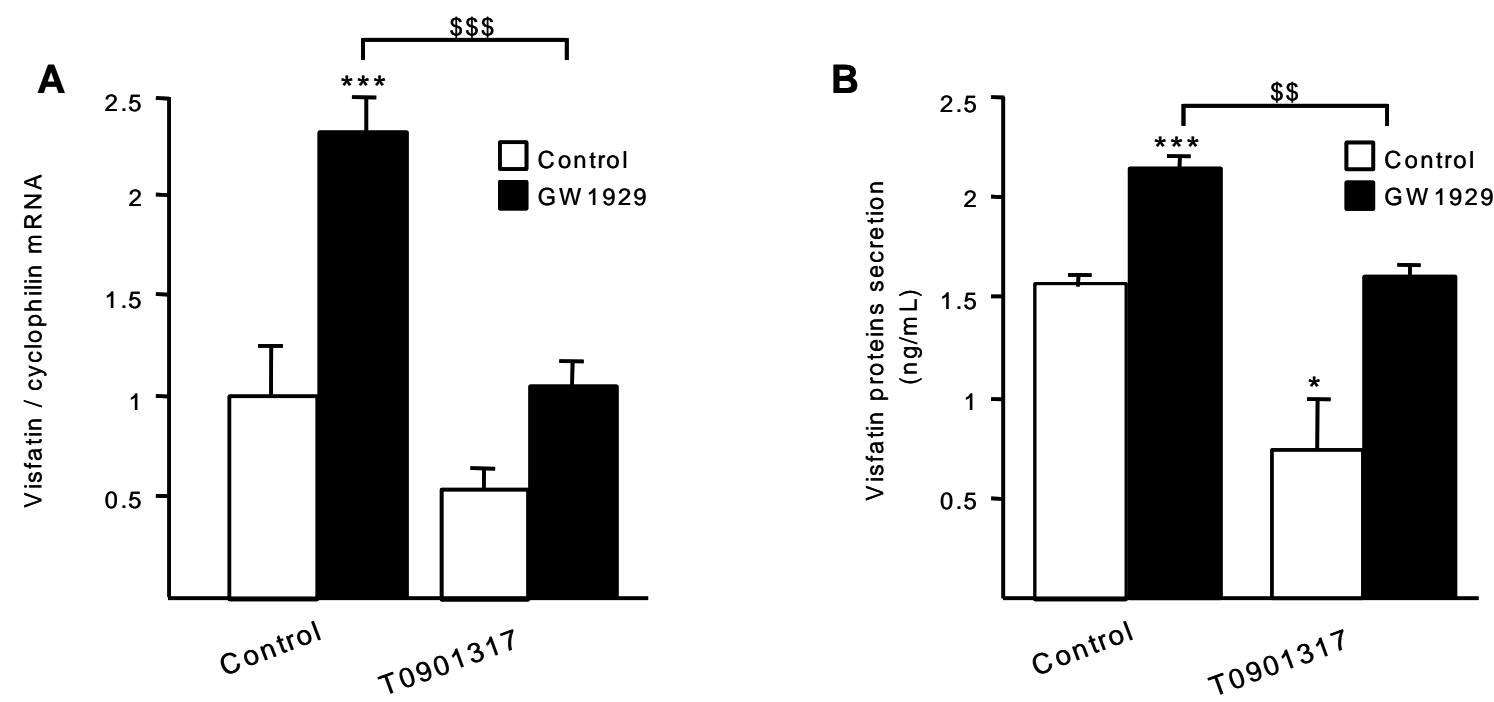

Figure 4 